\title{
Loading with Oral P2Y 12 Receptor Inhibitors: To Crush or Not to Crush?
}

\author{
Dimitrios Alexopoulos ${ }^{1}$ Stylianos Dragasis ${ }^{2}$ Nikolaos Kafkas ${ }^{2}$ \\ 1 2nd Department of Cardiology, Attikon University Hospital, National \\ and Kapodistrian University of Athens Medical School, Athens, \\ Greece \\ 2 Department of Cardiology, General Hospital of Attica "KAT", \\ Athens, Greece \\ Thromb Haemost 2019;119:1037-1047. \\ Address for correspondence Dimitrios Alexopoulos, MD, 2nd \\ Department of Cardiology, Attikon University Hospital, Rimini 1, \\ Chaidari 12462, Athens, Greece (e-mail: dalex@med.uoa.gr).
}

\begin{abstract}
Keywords

- anti-platelet agents

- clinical trials: antiplatelet drugs

- platelet pharmacology

Oral ${\mathrm{P} 2 \mathrm{Y}_{12}}_{12}$ receptor inhibitors represent a mainstay treatment in patients with acute coronary syndrome and those undergoing percutaneous coronary intervention. In the setting of ST-elevation myocardial infarction, when early platelet inhibition is highly desirable, the onset of action of oral $\mathrm{P}_{2} \mathrm{Y}_{12}$ receptor inhibitors is, however, delayed, likely due to delayed drug absorption. Crushing the tablets, which are to be used for patient loading with an oral $\mathrm{P}_{2} \mathrm{Y}_{12}$ receptor inhibitor, has been shown to provide earlier platelet inhibition than standard, integral tablets administration. Chewed ticagrelor tablets may also result in a similar effect. Such findings should be interpreted with caution, mainly due to the small number of patients enrolled and the nature (pharmacodynamic/pharmacokinetic) of the respective studies. Furthermore, in patients with out-of-hospital cardiac arrest, who remain comatose, crushing tablets is commonly applied in clinical practice for platelet $\mathrm{P}_{2} \mathrm{Y}_{12}$ receptor inhibition. In this review, we focus on current evidence regarding the role of crushed $\mathrm{P}_{2} \mathrm{Y}_{12}$ receptor inhibitor pills, analyzing clinical scenarios where most of the promise exists along with future expectations from this type of formulation. Large randomized studies are needed to draw firm conclusions regarding the clinical benefit of 'crushing' over the usual 'not-crushing' practice.
\end{abstract}

\section{Introduction}

Platelets play a key role in the pathogenesis of acute coronary syndromes (ACSs) and become highly activated particularly in ST-segment elevation myocardial infarction (STEMI) patients, as well as during percutaneous coronary intervention $(\mathrm{PCI}){ }^{1,2}$ During the last two decades, dual anti-platelet therapy consisting of a combination of aspirin and a P2Y 12 receptor inhibitor has been established as an essential therapy component for the treatment of ACS and/or PCI patients. Clopidogrel is the most broadly used oral $\mathrm{P}^{2} \mathrm{Y}_{12}$ receptor inhibitor worldwide; however, both prasugrel and ticagrelor exhibit a faster and more consistent platelet inhibition than clopidogrel, especially in STEMI patients. ${ }^{3-9}$ Accordingly, ticagrelor administered as a $180-\mathrm{mg}$ loading dose (LD) and 90-mg twice daily thereafter or prasugrel administered as a $60-\mathrm{mg}$ LD orally and $10 \mathrm{mg}$ once daily, are the preferred $\mathrm{P}_{2} \mathrm{Y}_{12}$ receptor inhibitors, provided there are no contraindications. ${ }^{10,11}$ In patients undergoing primary PCI several studies have pointed out the delayed onset of action of oral $\mathrm{P}_{2} \mathrm{Y}_{12}$ receptor inhibitors, most likely attributed to an impaired absorption. ${ }^{6,12-14}$ Opiates, commonly used for pain relief, appear to exacerbate this problem. ${ }^{15-19}$ Given the urgent need for strong and early platelet inhibition especially in this patient population, researchers have tried several ways to bridge this gap with the early LD received

February 27, 2019

accepted after revision

March 23, 2019 (c) 2019 Georg Thieme Verlag KG Stuttgart · New York
DOI https://doi.org/ 10.1055/s-0039-1688790. ISSN 0340-6245. 
administration even in the pre-hospital setting appearing as a promising strategy. ${ }^{20,21}$ However, expectations have clearly not been fulfilled with this approach. ${ }^{22-26}$ Crushing the tablets, which are to be used for patient loading with an oral $\mathrm{P}_{2} \mathrm{Y}_{12}$ receptor inhibitor, appears as a promising mode of administration able to expedite the onset of platelet inhibition. In this review, we will focus on current evidence regarding the role of crushed $\mathrm{P}_{2} \mathrm{Y}_{12}$ receptor inhibitor pills, analysing clinical scenarios where most of the promise exists along with future expectations from this type of formulation.

\section{How Tablets' Crushing is Performed?}

Intensive care units' personnel have traditionally used crushing to administer oral drugs in intubated patients through a nasogastric tube, provided that bioequivalence is maintained. Crushing involves a series of certain steps that ensures the dispersion of all the particles of each crushed tablet into purified water, to form a suspension, which is then administered to the patient. Crushing is performed in a mortar using a pestle for approximately 60 seconds. Thereafter, $20 \mathrm{~mL}$ of purified water is added and stirred for 60 seconds. The liquid is transferred to a dosing cup with the addition of another $15 \mathrm{~mL}$ of purified water. The mixture is then stirred to form a suspension. The same procedure is repeated with an additional $15 \mathrm{~mL}$ of purified water added to the mortar to rinse out any remaining drug. The total contents $(50 \mathrm{~mL})$ are stirred for another 30 seconds to ensure that all the remaining particles are dispersed. ${ }^{27}$ Crushing can be also performed using a commercially available syringe crusher, which allows for preparation of crushed tablets in an average time of 2 to 3 minutes. After five rotations of the crushing mechanism, $25 \mathrm{~mL}$ of water is aspirated into the syringe and mixed by shaking the crushed pill contents for 30 seconds. This suspension is then dispensed into a dosing cup. The syringe crusher is rinsed using an additional $25 \mathrm{~mL}$ of water and added to the dosing cup for a total of $50 \mathrm{~mL}$ suspension, which is then administered orally. ${ }^{28}$

\section{Oral P2Y 12 Receptor Inhibitors: Onset of Action in Various Clinical Settings}

Clopidogrel-a thienopyridine-is an inactive pro-drug, which requires in vivo oxidation by the hepatic or intestinal cytochrome CYP3A4 and 2C19 isoenzymes. It binds irreversibly to the $\mathrm{P}_{2} \mathrm{Y}_{12}$ receptor and inhibits platelet aggregation. In PCI candidates and non-ST-segment elevation ACS patients, clopidogrel's full anti-platelet effect appears within 2 hours after loading. ${ }^{29,30}$ However, its bioavailability is impaired in the setting of STEMI. ${ }^{6}$ Prasugrel is a newer generation thienopyridine that irreversibly inhibits the $\mathrm{P}^{2} \mathrm{Y}_{12}$ receptor, at the same site as clopidogrel. It is also a pro-drug, meaning that it requires to be converted in vivo to its active metabolite, primarily by CYP3A4 and CYP2B6. Prasugrel is approximately 5 to 9 times more potent than clopidogrel, with an onset of action within 1 hour., ${ }^{3,31}$ Ticagrelor, a cyclopentyl-triazolopyrimidine, is a reversible $\mathrm{P}_{2} \mathrm{Y}_{12}$ receptor inhibitor, with a plasma half-life of 12 hours.
It requires no hepatic activation as it is not a pro-drug and also exhibits a more rapid and consistent onset of action than clopidogrel, both in stable, as well as unstable coronary artery disease patients. ${ }^{5,32}$ Nevertheless, even the relatively fast-acting prasugrel and ticagrelor used in standard or even increased LD, exhibit a delay in their onset of action when administered in STEMI patients. ${ }^{12-14,33,34}$ As a consequence, a significant proportion of patients undergo primary $\mathrm{PCI}$ without adequate platelet inhibition, if standard oral $\mathrm{P}_{2} \mathrm{Y}_{12}$ administration is used. ${ }^{35}$ These observations fuelled the need to find alternative methods of administration, to facilitate drug absorption and expedite platelet inhibition.

\section{Early Studies with Crushing Clopidogrel or Ticagrelor Tablets}

Clopidogrel $300 \mathrm{mg}$ administered via a nasogastric tube in crushed form with $30 \mathrm{~mL}$ water was compared with oral tablet ingestion in nine healthy volunteers. ${ }^{36}$ Plasma concentration of its primary inactive metabolite peaked earlier and the median peak plasma concentration was $80 \%$ higher with crushed clopidogrel than with the whole tablets. Despite the study's small number of participants, it was clear that the crushed form of clopidogrel administered through a nasogastric tube exhibited significantly faster rates of absorption and increased bioavailability, compared with standard whole tablet administration, when an equal LD was given. One or two crushed $90 \mathrm{mg}$ ticagrelor tablets prepared for either oral or via a nasogastric tube administration, seem to deliver a mean dose of $\geq 97 \%$ of the intact tablet. ${ }^{37}$ In another study conducted in 36 healthy volunteers, crushing a single $90 \mathrm{mg}$ ticagrelor tablet and administered either orally or via a nasogastric tube resulted in increased plasma concentrations of both ticagrelor and its active metabolite ARC124910XX, at 0.5- and 1-hour postdose, when compared with whole-tablet ingestion. ${ }^{38}$ Plasma concentration-time profiles for both ticagrelor and ARC124910XX at 2 and 3 hours post-dose were comparable between the crushed and intact tablet administration treatment arms. Overall, bioequivalence was proved for crushed over whole-tablet preparations of ticagrelor regardless of oral or nasogastric tube administration.

\section{Crushing P2Y $_{12}$ Receptor Inhibitors Tablets in STEMI Patients}

Considering the aforementioned data, the idea was born that expedition of the onset of action of $\mathrm{P}_{2} \mathrm{Y}_{12}$ receptor inhibitors in STEMI may be achieved by crushing the integral tablets. The Mashed Or Just Integral pill of TicagrelOr (MOJITO) study was a prospective, randomized, four-centre study, which evaluated the role of equal doses (180 mg) of crushed versus integral ticagrelor tablets in STEMI patients undergoing primary PCI. ${ }^{27}$ Platelet reactivity was assessed by VerifyNow (Accumetrics, San Diego, California, United States) and expressed in $\mathrm{P}^{2} \mathrm{Y}_{12}$ reaction units (PRU). At 1-hour postloading, platelet reactivity was significantly lower in the crushed versus integral groups, 168 (interquartile range 
[IQR]: 61-251) versus 252 (IQR: 167-301), respectively, $p=0.006$. High on-treatment platelet reactivity was found in 35 and $63 \%$ of patients in the crushed and integral tablets groups, respectively, $p=0.011$. No differences in platelet reactivity were observed in later time points. Morphine administration was an independent predictor of high-platelet reactivity in the whole population. Crushing ticagrelor tablets did not increase adverse events. Main limitations of this study were the small sample size and the lack of a pharmacokinetic analysis. The OraL crushed and dispersed ticagrelor $180 \mathrm{mg}$ compared with whole tablets of eQUal dose in STEMI Patients unDergoing Primary PCI (LIQUID) study examined the pharmacokinetic and pharmacodynamic interactions of crushed ticagrelor administered in the semi-upright sitting position, in 20 patients with STEMI undergoing primary $\mathrm{PCI}^{39}$ Ticagrelor plasma exposure at 1 hour and area under the plasma concentration-time curve from time zero to 1 hour were higher in the crushed versus integral tablets group, while time to maximum plasma concentration was 2 versus 4 hours in the crushed versus integral tablets groups, respectively. Parallel findings were observed with AR-C124910XX, ticagrelor's active metabolite. A more potent anti-platelet activity was apparent during the first hour post-loading in the crushed ticagrelor group, which was attributed to the more rapid absorption and plasma exposure than with standard administration. LIQUID's major limitation was the small sample size and the fact that the study was not powered for pharmacodynamic superiority of the crushed tablet strategy versus the integral tablet strategy.

The pharmacokinetic and pharmacodynamic profiles of crushed versus whole prasugrel tablets in 50 STEMI patients undergoing primary $\mathrm{PCI}$ were described in the CRUSH study. ${ }^{28}$ The $60-\mathrm{mg}$ LD of crushed prasugrel provided reduced platelet reactivity as early as 30 minutes after drug administration. At 2 hours after loading, platelet reactivity in PRU (primary endpoint of the study), was reduced by crushed versus integral tablets: 95 versus 164, least-square means difference 68 (95\% confidence interval: 10-126), $p=0.022$. Parallel findings were observed with vasodilator-stimulated phosphoprotein (VASP) assay. Pharmacokinetic evaluation confirmed that crushed prasugrel was associated with an over threefold faster drug absorption and nearly twofold higher maximal plasma concentration of prasugrel's active metabolite in the first 2 hours postloading, compared with whole tablet administration. There were no adverse events related to crushed prasugrel. Based on the aforementioned studies, crushed ticagrelor or prasugrel instead of whole tablet administration, may be a preferable treatment option in patients presenting with STEMI and undergoing primary PCI, to achieve faster gastrointestinal absorption and platelet inhibition (-Fig. 1)..$^{40}$

\section{Alternative to Crushing Modes of Administration}

Although ticagrelor absorption does not seem to occur through the oral mucosa, chewing ticagrelor tablets has been tested as an alternative to crushing mode of administration. ${ }^{41}$ In a randomized study involving 99 stable angina patients, the 180-mg LD of crushed or chewed ticagrelor tablets achieved a more rapid platelet inhibition, when compared with the standard LD of integral tablets. ${ }^{42}$ Chewed ticagrelor seemed to exert faster and stronger platelet inhibition compared with crushed or integral tablets, at 20 and 60 minutes after the loading. Initiation of enzymatic metabolic degradation of ticagrelor in the mouth, due to its prolonged exposure to the saliva might contribute to this 'enhanced' platelet inhibition after the administration of the chewed ticagrelor formulation. However, given the small number of patient sample and the study's design (3:1:1 patient assignment to integral:crushed:chewed arms, respectively), the difference between crushed and chewed tablets should be regarded as hypothesis generating only. In another study, in 50 non-STEMI patients chewing a $180-\mathrm{mg}$ LD of ticagrelor provided faster and improved inhibition of platelets aggregation at 1-hour post-loading, compared with standard administration. ${ }^{43}$ Same investigators further described in 50 patients with STEMI and primary PCI an enhanced platelet inhibitory effect with chewed ticagrelor $180 \mathrm{mg}$, when compared with the swallowed LD of integral tablets. ${ }^{44}$ Reduced platelet reactivity with chewed ticagrelor was notable as early as 30 minutes and especially 1 hour after drug administration, while platelet inhibition curves between the two arms of the study converged about 3 to 4 hours after drug administration. Therefore, chewing ticagrelor tablets seems to be an effective way to expedite platelet inhibition, compared with integral tablets administration. Importantly, however, studies supporting chewing ticagrelor tablets lacked pharmacokinetic confirmation. On the other hand, sub-lingual administration of crushed ticagrelor tablets failed to prove superiority over crushed tablets given orally in a randomized study involving 49 unstable angina patients. ${ }^{45}$ Stronger platelet inhibition at 30 and 45 minutes was seen with crushed ticagrelor given orally instead of sub-lingually. Results within the first hour after the LD were also confirmed by pharmacokinetic analysis of ticagrelor and AR-C124900XX (active metabolite).

Studies with crushed or chewed tablets of $\mathrm{P}_{2} \mathrm{Y}_{12}$ receptor inhibitors in patients with coronary artery disease are summarized in - Table 1. In-hospital or at most 30 days' followup has been provided in these small-sized (20-99 patients each) studies, with no signs of excess bleeding or other adverse events with crushed or chewed tablets compared with standard, integral tablets administration. However, no clues regarding the clinical value of crushed or chewed modes of administration can be obtained from these purely pharmacodynamic/pharmacokinetic studies.

\section{Crushed P2Y 12 Receptor Inhibitors Tablets in Out-of-Hospital Cardiac Arrest Survivors}

Patients with out-of-hospital cardiac arrest (OHCA), who survive cardiac resuscitation, represent a particularly highrisk population of increasing interest. Most of these patients undergo emergency PCI while they remain comatose, 

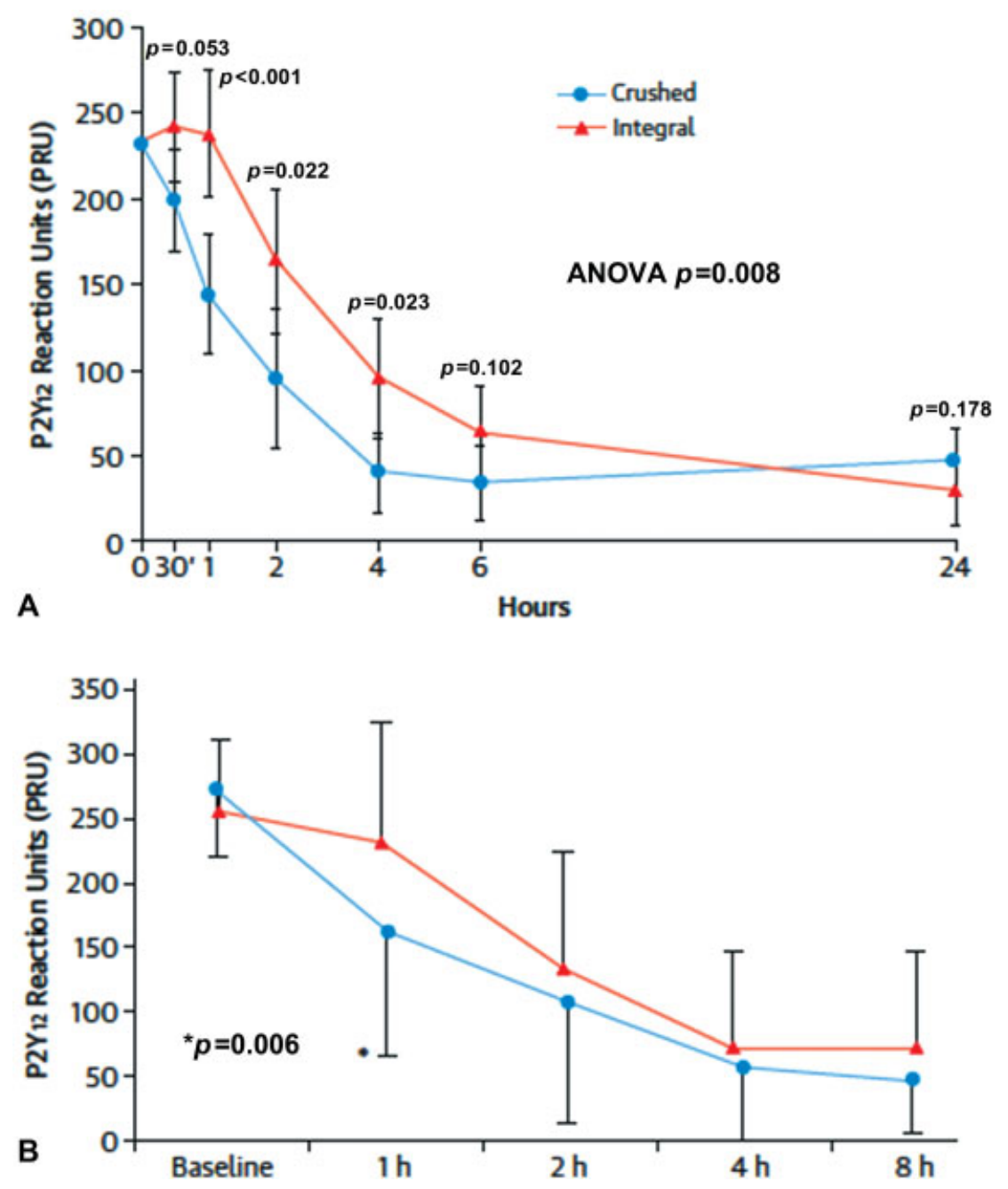

Fig. 1 PRU assessed by the VerifyNow P2Y 12 assay in patients treated with crushed or integral tablets. Results are from the CRUSH (Pharmacodynamic and Pharmacokinetic Profiles of Standard versus Crushed Prasugrel in Patients with ST-Segment Elevation Myocardial Infarction Undergoing Primary Percutaneous Coronary Intervention) trial (A) and the MOJITO (Mashed Or Just Integral pill of TicagrelOr) trial (B). Blue line indicates patients treated with crushed tablets; orange line indicates patients treated with integral tablets. Data are expressed as mean \pm standard deviation (SD). ANOVA, analysis of variance; PRU, platelet reactivity units. (Reprinted with permission from Sardella et al. ${ }^{40}$ )

intubated and unable to swallow oral $\mathrm{P}_{2} \mathrm{Y}_{12}$ receptor inhibitors. On the other hand, these patients are in utmost need of adequate platelet inhibition. In a randomized study of 37 comatose OHCA survivors undergoing PCI and hypothermia, crushed ticagrelor provided significantly faster and stronger platelet inhibition, 2 hours post-LD and for the 48-hour period, when compared with clopidogrel. ${ }^{46}$ In another study, in 40 patients with mild therapeutic hypothermia after cardiac arrest due to MI, platelet inhibition assessed by VASP was proved to be significantly worse during the first 24 hours in clopidogrel- than in ticagrelor- or prasugreltreated patients. ${ }^{47}$ Administration of crushed ticagrelor via a nasogastric tube appeared to reliably and effectively inhibit platelet function in vivo and in vitro, regardless of the presence of hypothermia. ${ }^{48}$ The early pharmacokinetic and pharmacodynamic effects of ticagrelor, when administered as crushed tablets through a nasogastric tube, were evaluated in the TICOMA study in 44 comatose OHCA patients who underwent primary $\mathrm{PCl}^{49}$ Sufficient platelet inhibition was achieved after 12 hours and in many cases earlier (at a median time of 3 hours). Of note, drug concentrations following the LD administration via the nasogastric tube were much lower than those reported for conscious patients from other studies.

Regarding clinical outcome in this patient population, lower rates of stent thrombosis during hospitalization have been reported with crushed ticagrelor when compared with clopidogrel, without differences in hemorrhagic events. ${ }^{50}$ In contrast, in another series, a higher rate of stent thrombosis was observed with novel $\mathrm{P}_{2} \mathrm{Y}_{12}$ receptor inhibitors compared with clopidogrel during a median of 2 days after $\mathrm{PCI} .{ }^{51}$ Both studies were retrospective. - Table 2 summarizes the existing data. 


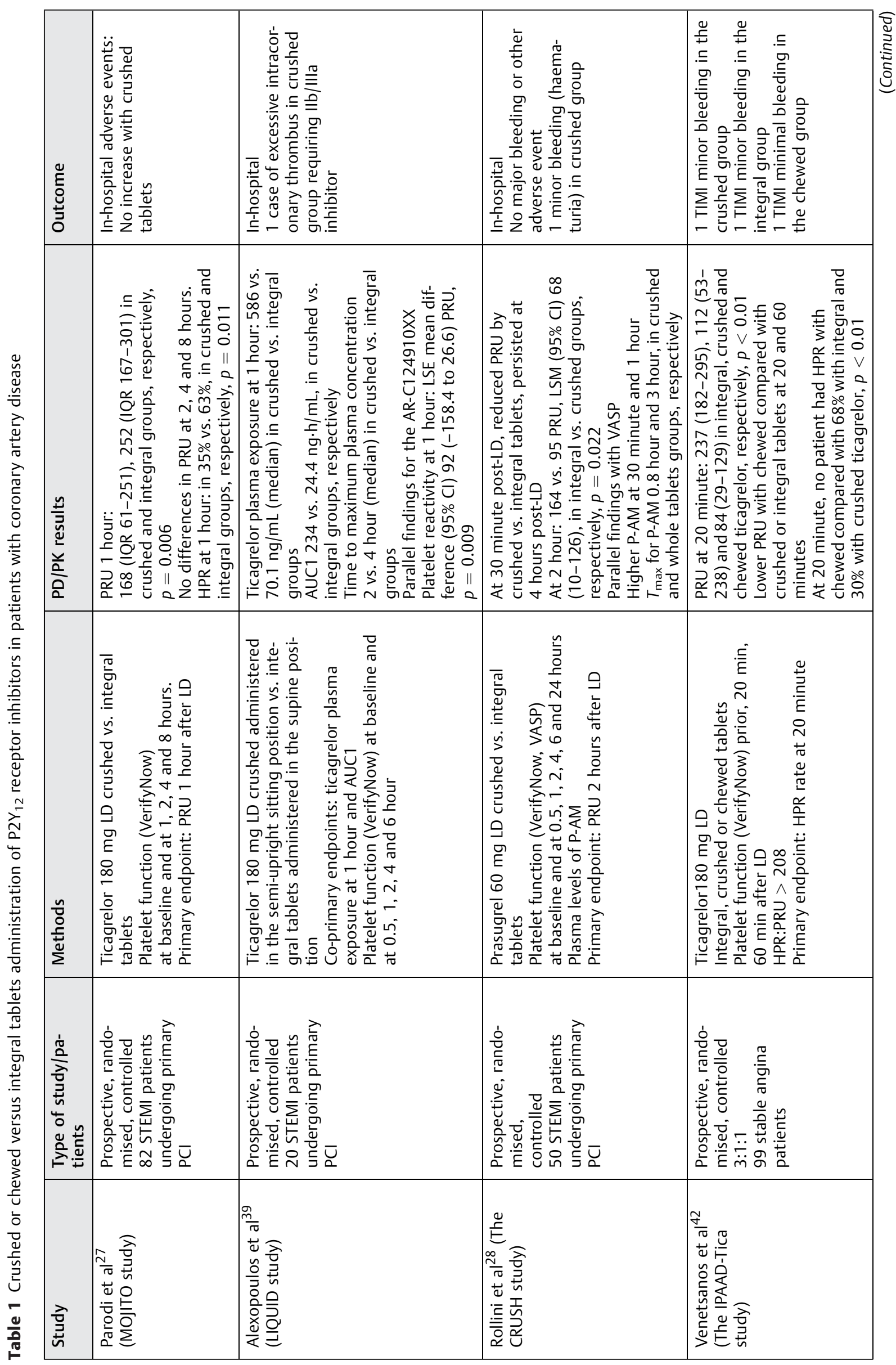



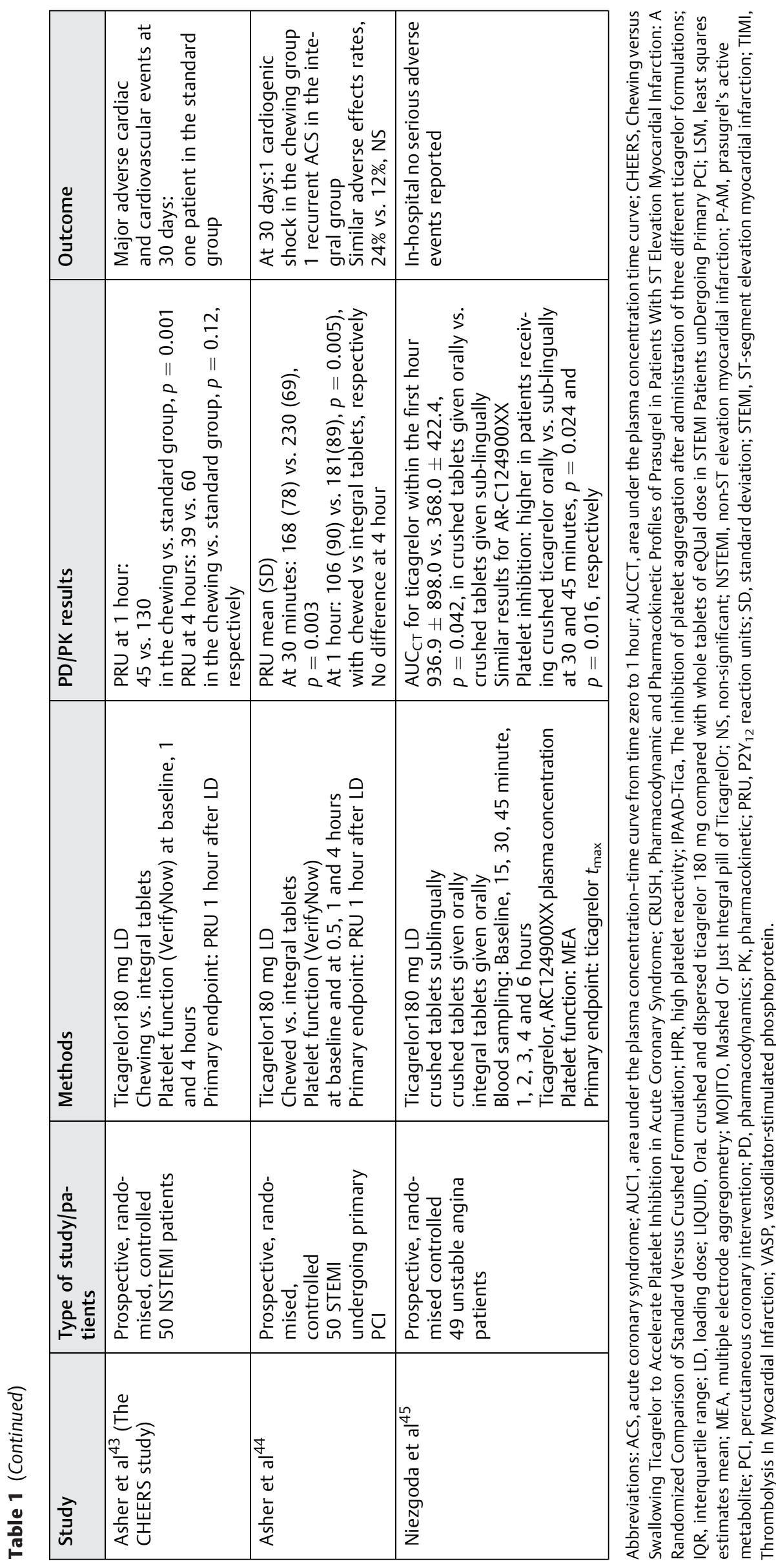


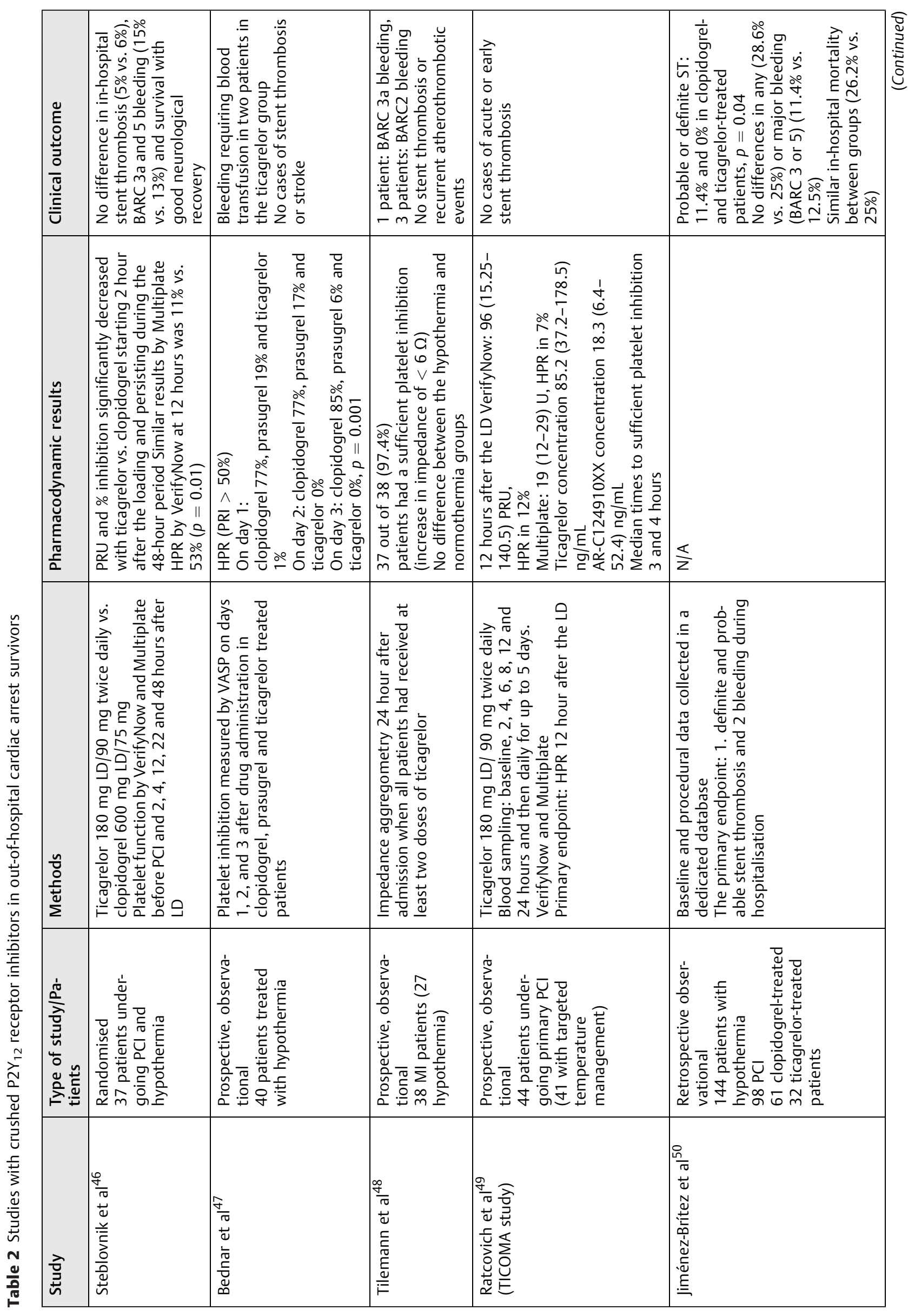




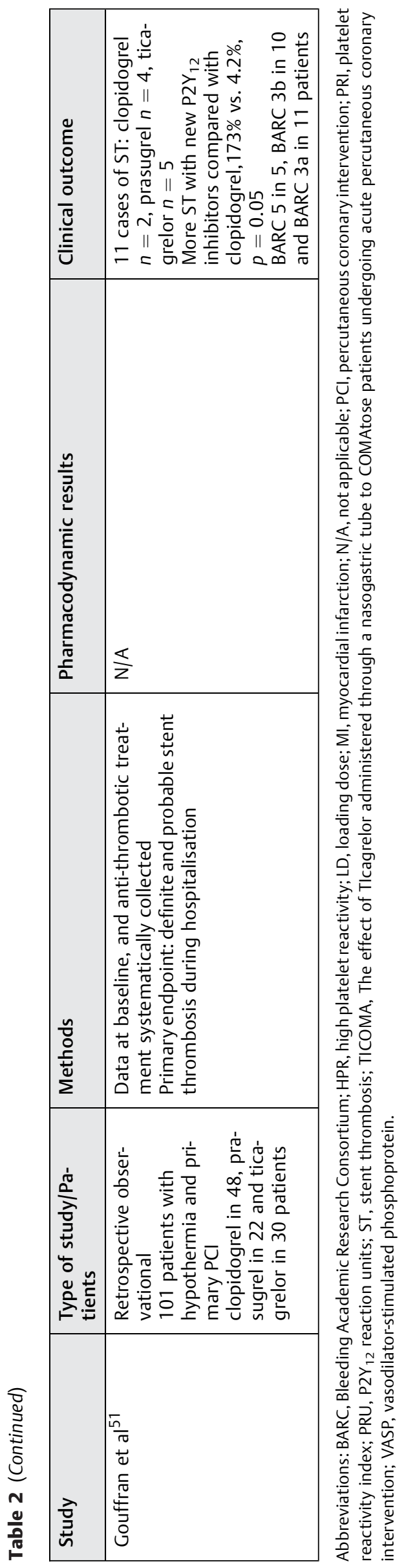

\section{Perspective}

Given evidence suggests that the crushed formulation of $\mathrm{P}_{2} \mathrm{Y}_{12}$ receptor inhibitors tablets appears as an appealing way to overcome, at least partially, the delayed onset of action observed in STEMI patients. Although many centers apply this technique, this superiority of crushing versus standard administration is based on small-sized, pharmacodynamic/pharmacokinetic studies, which have not been designed for clinical outcome differences assessment. However, a recent meta-analysis of clinical studies has clearly shown that an early effective $\mathrm{P}_{2} \mathrm{Y}_{12}$ inhibition is desirable, as it significantly reduces ischemic events, without an increase in major bleedings. ${ }^{52} \mathrm{~A}$ similar concept is supported by a clinical outcome study of the intravenously administered $\mathrm{P}_{2} \mathrm{Y}_{12}$ receptor inhibitors cangrelor, as tested over clopidogrel. ${ }^{53}$ In the very recently published CANTIC (Platelet Inhibition With CANgrelor and Crushed TICagrelor in STEMI Patients Undergoing Primary Percutaneous Coronary Intervention) study, cangrelor was compared with placebo in 50 patients all of whom had been loaded with crushed ticagrelor $180 \mathrm{mg}$ LD. Platelet reactivity (assessed by VerifyNow and VASP assays) was reduced by cangrelor versus placebo as early as 5 minutes post-bolus, at 30 minutes (primary endpoint of the study) and during the whole duration of cangrelor infusion. No signs of drug-drug interactions between cangrelor and crushed ticagrelor were observed with concomitant administration of these agents. ${ }^{54}$ The authors characterized 'crushed' as the fastest-acting formulation of $\mathrm{P}_{2} \mathrm{Y}_{12}$ receptor inhibitors available. Nevertheless, it has to be recognized that up to one-third of STEMI patients loaded with crushed formulation may still have a high platelet reactivity levels at 2 hours post-LD, ${ }^{54}$ which is a wellestablished predictor of thrombotic complications. Furthermore, it is arguable that in the context of almost immediate platelet inhibition, which is obtained by cangrelor, the use of crushed tablets of $\mathrm{P}_{2} \mathrm{Y}_{12}$ receptor inhibitors may be futile. However, cangrelor involves a more complex mode of administration (bolus plus infusion), it is expensive and without proven clinical superiority over the novel $\mathrm{P}_{2} \mathrm{Y}_{12}$ receptor inhibitors. Moreover, transition from the intravenous agent to oral tablets is inevitable and crushing them is likely to represent the ideal mode of administration. Of note, the potential of drug-drug interaction during transition from cangrelor to prasugrel has been raised, although there are no data regarding crushed prasugrel and cangrelor coadministration. ${ }^{55}$

Crushing could potentially ameliorate the adverse effect of morphine on platelet inhibition. ${ }^{15-19}$ This ability has been disputed by some investigators ${ }^{42}$ and relevant data are scarce. Morphine-treated patients presented higher platelet reactivity than non-morphine ones in the crushed group of the MOJITO study. ${ }^{27}$ However, in the CRUSH study, morphine (used in 76\% of the whole population and $85 \%$ in the crushed prasugrel group), was not associated with any significant difference on the primary endpoint (PRU at 2 hours), as well as during the overall 24-hour study time course. ${ }^{28}$ In both studies, results were based on secondary analyses, with very 
small patients numbers, and do not clearly support or exclude a potential interaction between morphine and crushing.

On-going studies are expected to provide further evidence on the role of crushing in the early STEMI phase. In the COMPARison of Pre-hospital CRUSHed versus Uncrushed Prasugrel Tablets in Patients With STEMI Undergoing primary PCI (CompareCrush) study, pre-hospital administration of crushed versus uncrushed prasugrel is evaluated. Coprimary endpoints are the percentage of patients with Thrombolysis In Myocardial Infarction flow grade 3 at initial angiography or a $\geq 70 \%$ ST-segment resolution directly postPCI (ClinicalTrials.gov Identifier: NCT03296540). An orodispersible tablet of ticagrelor has also been developed. This is designed to dissolve or disintegrate on the tongue rather than being swallowed whole and could be suitable for patients with swallowing difficulties and who are unable to swallow whole tablets. Promising results have been described in healthy volunteers with reports of a bioequivalence between the orodispersible and the immediate release tablet. ${ }^{56}$ Nevertheless, comparison between the orodispersible and the crushed, film-coated tablets of ticagrelor has not been performed so far.

Intubated or comatose patients likely represent the 'ideal' population for administration of $\mathrm{P}_{2} \mathrm{Y}_{12}$ receptor inhibitors in a crushed form through a nasogastric tube. Crushing is in widely spread use in unconscious patients following OHCA. Of note, ticagrelor prescribing information supports crushing for patients who are unable to swallow whole tablets and the administration of the mixture via a nasogastric tube. ${ }^{57}$ Patients with prior stroke or dysphagia, or those who have been sedated, are other potential candidates for crushed $\mathrm{P}_{2} \mathrm{Y}_{12}$ receptor inhibitors tablets administration.

\section{Conclusion}

In patients with OHCA, who remain comatose, crushing tablets is applied in clinical practice for platelet $\mathrm{P}_{2} \mathrm{Y}_{12}$ receptor inhibition. In patients suffering from STEMI, current data likely support the superiority of crushed ticagrelor or prasugrel versus the administration of standard integral tablets orally. Crushed formulations of ticagrelor and prasugrel undoubtedly exhibit early signs of successful platelet inhibition, starting as soon as 30 minutes after their administration, without any bleeding concern. Larger randomized studies would be useful to draw firm conclusions and establish solid evidence on the net clinical benefit of 'crushing' over the usual 'not-crushing' practice. In their absence, as the use of crushing is not associated with any downside, it may be considered also in routine practice and not only in specific scenarios, if this is not associated with any delays.

\section{Funding}

None.

\section{Conflict of Interest}

D.A. has received lecturing honoraria/advisory board fees from Astrazeneca, Bayer, Boehringer Ingelheim, AMGEN,
Chiesi Hellas, Medtronic, Biotronik. Other authors have no disclosure.

\section{References}

1 Alexopoulos D. P2Y12 inhibitors adjunctive to primary PCI therapy in STEMI: fighting against the activated platelets. Int J Cardiol 2013;163(03):249-255

2 Alexopoulos D, Xenogiannis I, Vlachakis P, Tantry U, Gurbel PA. Peri-procedural platelet reactivity in percutaneous coronary intervention. Thromb Haemost 2018;118(07):1131-1140

3 Wallentin L, Varenhorst C, James S, et al. Prasugrel achieves greater and faster P2Y12receptor-mediated platelet inhibition than clopidogrel due to more efficient generation of its active metabolite in aspirin-treated patients with coronary artery disease. Eur Heart J 2008;29(01):21-30

4 Zhu B, Effron MB, Kulkarni MP, et al. The onset of inhibition of platelet aggregation with prasugrel compared with clopidogrel loading doses using gatekeeping analysis of integrated clinical pharmacology data. J Cardiovasc Pharmacol 2011;57(03): 317-324

5 Gurbel PA, Bliden KP, Butler K, et al. Randomized double-blind assessment of the ONSET and OFFSET of the antiplatelet effects of ticagrelor versus clopidogrel in patients with stable coronary artery disease: the ONSET/OFFSET study. Circulation 2009;120 (25):2577-2585

6 Heestermans AA, van Werkum JW, Taubert D, et al. Impaired bioavailability of clopidogrel in patients with a ST-segment elevation myocardial infarction. Thromb Res 2008;122:776-781

7 Alexopoulos D, Theodoropoulos KC, Stavrou EF, et al. Prasugrel versus high dose clopidogrel to overcome early high on clopidogrel platelet reactivity in patients with ST elevation myocardial infarction. Cardiovasc Drugs Ther 2012;26(05):393-400

8 Zeymer U, Mochmann HC, Mark B, et al. Double-blind, randomized, prospective comparison of loading doses of $600 \mathrm{mg}$ clopidogrel versus $60 \mathrm{mg}$ prasugrel in patients with acute STsegment elevation myocardial infarction scheduled for primary percutaneous intervention: the ETAMI trial (early thienopyridine treatment to improve primary $\mathrm{PCI}$ in patients with acute myocardial infarction). JACC Cardiovasc Interv 2015;8(1 Pt B):147-154

9 Alexopoulos D, Kontoprias K, Gkizas V, et al. Ticagrelor vs clopidogrel followed by ticagrelor re-loading in patients with STsegment elevation myocardial infarction undergoing primary percutaneous coronary intervention: a randomized, pharmacodynamic comparison. Platelets 2016;27(05):420-426

10 Levine GN, Bates ER, Blankenship JC, et al. 2015 ACC/AHA/SCAI focused update on primary percutaneous coronary intervention for patients with ST-elevation myocardial infarction: an update of the $2011 \mathrm{ACCF} / \mathrm{AHA} / \mathrm{SCAI}$ guideline for percutaneous coronary intervention and the $2013 \mathrm{ACCF} / \mathrm{AHA}$ guideline for the management of ST-elevation myocardial infarction: a report of the American College of Cardiology/American Heart Association Task Force on Clinical Practice Guidelines and the Society for Cardiovascular Angiography and Interventions. Circulation 2016; 133(11):1135-1147

11 Ibanez B, James S, Agewall S, et al; ESC Scientific Document Group. 2017 ESC Guidelines for the management of acute myocardial infarction in patients presenting with ST-segment elevation: the Task Force for the management of acute myocardial infarction in patients presenting with ST-segment elevation of the European Society of Cardiology (ESC). Eur Heart J 2018;39(02):119-177

12 Alexopoulos D, Xanthopoulou I, Gkizas V, et al. Randomized assessment of ticagrelor versus prasugrel antiplatelet effects in patients with ST-segment-elevation myocardial infarction. Circ Cardiovasc Interv 2012;5(06):797-804 
13 Parodi G, Valenti R, Bellandi B, et al. Comparison of prasugrel and ticagrelor loading doses in ST-segment elevation myocardial infarction patients: RAPID (Rapid Activity of Platelet Inhibitor Drugs) primary PCI study. J Am Coll Cardiol 2013;61(15): 1601-1606

14 Franchi F, Rollini F, Cho JR, et al. Impact of escalating loading dose regimens of ticagrelor in patients with ST-segment elevation myocardial infarction undergoing primary percutaneous coronary intervention: results of a prospective randomized pharmacokinetic and pharmacodynamic investigation. JACC Cardiovasc Interv 2015;8(11):1457-1467

15 Kubica J, Adamski P, Ostrowska M, et al. Morphine delays and attenuates ticagrelor exposure and action in patients with myocardial infarction: the randomized, double-blind, placebo-controlled IMPRESSION trial. Eur Heart J 2016;37(03):245-252

16 Parodi G, Bellandi B, Xanthopoulou I, et al. Morphine is associated with a delayed activity of oral antiplatelet agents in patients with ST-elevation acute myocardial infarction undergoing primary percutaneous coronary intervention. Circ Cardiovasc Interv 2014;8(01):e001593

17 Giannopoulos G, Deftereos S, Kolokathis F, Xanthopoulou I, Lekakis J, Alexopoulos D. P2Y12 receptor antagonists and morphine: a dangerous liaison? Circ Cardiovasc Interv 2016;9(09):e004229

18 Thomas MR, Morton AC, Hossain R, et al. Morphine delays the onset of action of prasugrel in patients with prior history of STelevation myocardial infarction. Thromb Haemost 2016;116(01): 96-102

19 Silvain J, Storey RF, Cayla G, et al. P2Y12 receptor inhibition and effect of morphine in patients undergoing primary PCI for STsegment elevation myocardial infarction. The PRIVATE-ATLANTIC study. Thromb Haemost 2016;116(02):369-378

20 Alexopoulos D, Bhatt DL, Hamm CW, Steg PG, Stone GW. Early P2Y12 inhibition in ST-segment elevation myocardial infarction: bridging the gap. Am Heart J 2015;170(01):3-12

21 Franchi F, Rollini F, Angiolillo DJ. Antithrombotic therapy for patients with STEMI undergoing primary PCI. Nat Rev Cardiol 2017;14(06):361-379

22 Koul S, Smith JG, Scherstén F, James S, Lagerqvist B, Erlinge D. Effect of upstream clopidogrel treatment in patients with STsegment elevation myocardial infarction undergoing primary percutaneous coronary intervention. Eur Heart J 2011;32(23): 2989-2997

23 Dörler J, Edlinger M, Alber HF, et al; Austrian Acute PCI Investigators. Clopidogrel pre-treatment is associated with reduced inhospital mortality in primary percutaneous coronary intervention for acute ST-elevation myocardial infarction. Eur Heart J 2011;32(23):2954-2961

24 Zeymer U, Arntz HR, Mark B, et al. Efficacy and safety of a high loading dose of clopidogrel administered prehospitally to improve primary percutaneous coronary intervention in acute myocardial infarction: the randomized CIPAMI trial. Clin Res Cardiol 2012;101(04):305-312

25 Montalescot G, van 't Hof AW, Lapostolle F, et al; ATLANTIC Investigators. Prehospital ticagrelor in ST-segment elevation myocardial infarction. N Engl J Med 2014;371(11):1016-1027

26 Capodanno D, Angiolillo DJ. Pretreatment with antiplatelet drugs in invasively managed patients with coronary artery disease in the contemporary era: review of the evidence and practice guidelines. Circ Cardiovasc Interv 2015;8(03):e002301

27 Parodi G, Xanthopoulou I, Bellandi B, et al. Ticagrelor crushed tablets administration in STEMI patients: the MOJITO study. J Am Coll Cardiol 2015;65(05):511-512

28 Rollini F, Franchi F, Hu J, et al. Crushed prasugrel tablets in patients with STEMI undergoing primary percutaneous coronary intervention: the CRUSH Study. J Am Coll Cardiol 2016;67(17): 1994-2004

29 Hochholzer W, Trenk D, Frundi D, et al. Time dependence of platelet inhibition after a $600-\mathrm{mg}$ loading dose of clopidogrel in a large, unselected cohort of candidates for percutaneous coronary intervention. Circulation 2005;111(20):2560-2564

30 Montalescot G, Sideris G, Meuleman C, et al; ALBION Trial Investigators. A randomized comparison of high clopidogrel loading doses in patients with non-ST-segment elevation acute coronary syndromes: the ALBION (Assessment of the Best Loading Dose of Clopidogrel to Blunt Platelet Activation, Inflammation and Ongoing Necrosis) trial. J Am Coll Cardiol 2006;48(05):931-938

31 Michelson AD, Frelinger AL III, Braunwald E, et al; TRITON-TIMI 38 Investigators. Pharmacodynamic assessment of platelet inhibition by prasugrel vs. clopidogrel in the TRITON-TIMI 38 trial. Eur Heart J 2009;30(14):1753-1763

32 Storey RF, Angiolillo DJ, Patil SB, et al. Inhibitory effects of ticagrelor compared with clopidogrel on platelet function in patients with acute coronary syndromes: the PLATO (PLATelet inhibition and patient Outcomes) PLATELET substudy. J Am Coll Cardiol 2010;56(18):1456-1462

33 Alexopoulos D, Gkizas V, Patsilinakos S, et al. Double versus standard loading dose of ticagrelor: onset of antiplatelet action in patients with STEMI undergoing primary PCI. J Am Coll Cardiol 2013;62(10):940-941

34 Alexopoulos D, Makris G, Xanthopoulou I, et al. Onset of antiplatelet action with high $(100 \mathrm{mg})$ versus standard $(60 \mathrm{mg})$ loading dose of prasugrel in patients with ST-segment-elevation myocardial infarction undergoing primary percutaneous coronary intervention: pharmacodynamic study. Circ Cardiovasc Interv 2014;7(02):233-239

35 Agrawal K, Bhatt DL. Antiplatelet therapy: does prasugrel or ticagrelor suffice in patients with STEMI? Nat Rev Cardiol 2013; 10(03):121-122

36 Zafar MU, Farkouh ME, Fuster V, Chesebro JH. Crushed clopidogrel administered via nasogastric tube has faster and greater absorption than oral whole tablets. J Interv Cardiol 2009;22(04): 385-389

37 Crean B, Finnie C, Crosby A. Evaluation of crushed ticagrelor tablet doses: recovery following crushing and naso-gastric tube passage ex vivo. Drugs R D 2013;13(02):153-157

38 Teng R, Carlson G, Hsia J. An open-label, randomized bioavailability study with alternative methods of administration of crushed ticagrelor tablets in healthy volunteers. Int J Clin Pharmacol Ther 2015;53(02):182-189

39 Alexopoulos D, Barampoutis N, Gkizas V, et al. Crushed versus integral tablets of ticagrelor in ST-segment elevation myocardial infarction patients: a randomized pharmacokinetic/pharmacodynamic study. Clin Pharmacokinet 2016;55(03):359-367

40 Sardella G, Calcagno S, Mancone M. Different prasugrel administration in STEMI patients: go faster and no fear to crush!. J Am Coll Cardiol 2016;67(17):2005-2007

41 Rollini F, Franchi F, Angiolillo DJ. Oral trans-mucosal administration of ticagrelor: is this really the future? Thromb Haemost 2017; 117(05):826-828

42 Venetsanos D, Sederholm Lawesson S, Swahn E, Alfredsson J. Chewed ticagrelor tablets provide faster platelet inhibition compared to integral tablets: the inhibition of platelet aggregation after administration of three different ticagrelor formulations (IPAAD-Tica) study, a randomised controlled trial. Thromb Res 2017;149:88-94

43 Asher E, Frydman S, Katz M, et al; For The PLATIS (Platelets and Thrombosis in Sheba) Study Group. Chewing versus swallowing ticagrelor to accelerate platelet inhibition in acute coronary syndrome - the CHEERS study. Thromb Haemost 2017;117(04): 727-733

44 Asher E, Tal S, Mazin I, et al. Effect of chewing vs swallowing ticagrelor on platelet inhibition in patients with ST-segment elevation myocardial infarction: a randomized clinical trial. JAMA Cardiol 2017;2(12):1380-1384

45 Niezgoda P, Sikora J, Barańska M, et al. Crushed sublingual versus oral ticagrelor administration strategies in patients with unstable 
angina. A pharmacokinetic/pharmacodynamic study. Thromb Haemost 2017;117(04):718-726

46 Steblovnik K, Blinc A, Mijovski MB, Fister M, Mikuz U, Noc M. Ticagrelor versus clopidogrel in comatose survivors of out-ofhospital cardiac arrest undergoing percutaneous coronary intervention and hypothermia: a randomized study. Circulation 2016; 134(25):2128-2130

47 Bednar F, Kroupa J, Ondrakova M, Osmancik P, Kopa M, Motovska Z. Antiplatelet efficacy of P2Y12 inhibitors (prasugrel, ticagrelor, clopidogrel) in patients treated with mild therapeutic hypothermia after cardiac arrest due to acute myocardial infarction. J Thromb Thrombolysis 2016;41(04):549-555

48 Tilemann LM, Stiepak J, Zelniker T, et al. Efficacy of enteral ticagrelor in hypothermic patients after out-of-hospital cardiac arrest. Clin Res Cardiol 2016;105(04):332-340

49 Ratcovich H, Sadjadieh G, Andersson HB, et al. The effect of TIcagrelor administered through a nasogastric tube to COMAtose patients undergoing acute percutaneous coronary intervention: the TICOMA study. EuroIntervention 2017;12(14):1782-1788

50 Jiménez-Brítez G, Freixa X, Flores-Umanzor E, et al. Out-ofhospital cardiac arrest and stent thrombosis: Ticagrelor versus clopidogrel in patients with primary percutaneous coronary intervention under mild therapeutic hypothermia. Resuscitation 2017;114:141-145

51 Gouffran G, Rosencher J, Bougouin W, et al. Stent thrombosis after primary percutaneous coronary intervention in comatose survivors of out-of-hospital cardiac arrest: are the new P2Y12 inhibitors really more effective than clopidogrel? Resuscitation 2016;98:73-78

52 Bellemain-Appaix A, Bégué C, Bhatt DL, et al. The efficacy of early versus delayed P2Y12 inhibition in percutaneous coronary intervention for ST-elevation myocardial infarction: a systematic review and meta-analysis. EuroIntervention 2018; 14(01):78-85

53 Bhatt DL, Stone GW, Mahaffey KW, et al; CHAMPION PHOENIX Investigators. Effect of platelet inhibition with cangrelor during PCI on ischemic events. N Engl J Med 2013;368(14):1303-1313

54 Franchi F, Rollini F, Rivas A, et al. Platelet inhibition with cangrelor and crushed ticagrelor in patients with ST-elevation myocardial infarction undergoing primary percutaneous coronary intervention. Circulation 2019;139(14):1661-1670

55 Angiolillo DJ, Rollini F, Storey RF, et al. International expert consensus on switching platelet $\mathrm{P}_{2} \mathrm{Y}_{12}$ receptor-inhibiting therapies. Circulation 2017;136(20):1955-1975

56 Teng R, Hammarberg M, Carlson GF, Bokelund-Singh S, Ruderfelt T, Blychert E. Pharmacokinetic profiles of ticagrelor orodispersible tablets in healthy western and Japanese subjects. Clin Drug Investig 2017;37(11):1035-1045

57 AstraZeneca LP. Brilinta (ticagrelor) tablets. Approved prescribing information. Available at: https://www.ema.europa.eu/en/documents/product-information/brilique-epar-product-information_en.pdf. Accessed February 26, 2019 